\title{
A Critical Review of Economic Evaluations of Trastuzumab in the Treatment of Early Stage HER2 Positive Breast Cancer
}

Quynh-Nga Thi Nguyen'1, Hoa Quoc Nguyen² and Ciaran O'Neill**

${ }^{1}$ Centre for Public Health, School of Medicine, Dentistry and Biomedical Sciences, Queen's University Belfast, Northern Ireland, UK

${ }^{2}$ School of Pharmacy, Queen's University Belfast, Northern Ireland, UK

\begin{abstract}
Eleven years after Trastuzumab was approved for use in the treatment of early stage human epidermal growth factor receptor positive breast cancer (HER2+) its clinical benefit has been demonstrated in short and long term follow up studies. The cost-effectiveness of the therapy in this context remains the subject of debate with a wide range of Incremental Cost Effectiveness Ratios (ICERs) reported in the literature. While several reviews of the literature have been undertaken these have not provided a critical analysis of the factors that might underlie this heterogeneity. In this review we provide a critical overview of the literature and discuss potential sources of heterogeneity in reported ICERs. We identify gaps in the current literature and provide a rationale for filling these gaps.
\end{abstract}

Keywords: Tumour; Histology; Clinical; Pathological; Disease; Hormone; Health

\section{Introduction to Breast Cancer}

Cancer is a leading cause of morbidity and mortality globally $[1,2]$. Breast cancer is the second most common type of cancer [1] and is the fifth leading source of cancer death [3]. The disease is more common in Northern Europe and North America than in other part of the world [4]. In the UK, approximately 1 in 8 women will be diagnosed with breast cancer during their lifetime [5]. Major risk factors for breast cancer include: female sex; increasing age; family history; reproductive factors (consisting of early menarche, late menopause, first live childbirth after age 30, nulliparity); long term use of hormone replacement therapy; previous exposure to therapeutic chest wall irradiation; benign proliferative breast disease; increased mammographic breast density; and genetic mutations (such as of the BRCA $1 / 2$ genes) $[1,6]$. Factors determining treatment decisions include: tumour histology, clinical and pathological characteristics of the primary tumour, metastatic disease status, patient age, hormone receptor (estrogen and progesterone receptors) and HER2 status (human epidermal growth factor receptor 2) [6]. Interventions can be classified as primary, secondary, or tertiary prevention [7]. In the case of breast cancer, primary prevention may include chemoprevention, pre-emptive mastectomy and health education; secondary prevention may include population screening and subsequent treatment as appropriate and tertiary prevention may include chemotherapy, surgery and radiation therapy [8].

While it is common in economic studies of breast cancer to refer to it as if it was one disease, in reality this is not the case. There are up to 21 distinct histological subtypes and at least four different molecular subtypes of breast cancer that are biologically different in presentation, response to therapy and outcomes as well as having distinct risk factors [9-14]. Distinctions between types relate to the hormone receptor status (HR+/HR-) and excess levels of human epidermal growth factor-a growth-promoting protein-receptor 2 status (HER2+/HER2-). The four main molecular subtypes are: Luminal A (HR+/HER2)-accounting for about $74 \%$ of breast cancers which tend to be slow growing and less aggressive than other subtypes) [15,16]; Triple negative (HR-/HER2) (accounting for about $12 \%$ of cancers [16,17]-typically with poorer short-term outcome); Luminal B (HR+/HER+) (accounting for about $10 \%$ and tend to be more aggressive than Luminal A breast cancers) [18] and; HER2- enriched (HR-/HER2+) (accounting or about $4 \%$ of breast cancers which tend to be more aggressive than other types of breast cancer and to have had poorer short-term outcomes than other estrogen receptor positive breast cancers though this has changed with the recent emergence of new therapies.

As detection and treatment of breast cancer has improved so too have survival rates [19]. Five-year relative survival rates have improved from nearly 75\% between 1975 and 1979 to approximately $90 \%$ in 2010 [20] though these vary depending between specific types of breast cancer as well as on stage of diagnosis and access to care [1]. Improvements in survival, increased incidence and the adoption of more expensive therapies has seen the economic burden of breast cancer rise [21,22] both for health services and society more broadly [21]. In high income countries, costs in terms of lost production may be particularly high as the disease tends to affect women when they are often most economically active-aged 35 to 70 . While there is a limited research on the economic burden of breast cancer [23], Taylor claim that breast cancer generally accounted for $10-20 \%$ of all cancer service costs, or approximately $0.15 \%$ of the average GDP in Europe (excluding productivity loss) [21]. In one population-based cost analysis in Europe, breast cancer was estimated to cost $€ 15$ billion (12\% of total cancer cost) [24] making the second single biggest contribution to overall cancer costs [22]. Studies that have focused on cost that fall outside the health service-productivity losses, out of pocket expenditure, informal carer costs-indicate substantial costs also. For example, it is estimated that a woman with breast cancer missed an average of 68.6 days from work for surgery, radiation and chemotherapy [25]; $20 \%$ of employed patients stopped work at 16 months after diagnosis; $12 \%$ decreased working time [26]; and mean duration of sick leave was $104.35 \pm 99.23$ days [27].

*Corresponding author: Ciaran O'Neill, Centre for Public Health, School of Medicine, Dentistry and Biomedical Sciences, Queen's University Belfast, UK NUI Galway, Northern Ireland, Tel: +442890978928; E-mail: Ciaran.oneill@qub.ac.uk

Received August 09, 2017; Accepted August 26, 2017; Published August 31, 2017

Citation: Nguyen QNT, Nguyen HQ, O'Neill C (2017) A Critical Review of Economic Evaluations of Trastuzumab in the Treatment of Early Stage HER2 Positive Breast Cancer. Pharmacoeconomics 2: 111. doi:10.4172/2472-1042.1000111

Copyright: (C) 2017 Nguyen QNT, et al. This is an open-access article distributed under the terms of the Creative Commons Attribution License, which permits unrestricted use, distribution, and reproduction in any medium, provided the original author and source are credited. 
Given the significant and increasing economic burden of breast cancer-and indeed of healthcare generally-it is not surprising that the relative value for money of alternative therapies has come under increasing scrutiny. Many countries now use economic evaluations to compare the alternative use of healthcare resources in terms of both cost and effect. Relative value for money is often expressed in terms of an Incremental Cost Effectiveness Ratio (ICER) showing the ratio of the additional cost relative to the additional effect of one therapy relative to another (The lower the ICER, the lower the ratio of cost to benefit and the better value for money). Often the effect is expressed in terms of incremental "quality adjusted life years"-QALY. These combine the additional years of life with the quality in which that life is experienced and when related to cost the resulting ICER can be compared against national thresholds as to what is considered an acceptable level of value [28]. In breast cancer, generally early stage interventions are associated with more favorable ICERs than late stage interventions [29,30]. Explanations for this relate both to higher costs typically incurred with late stage treatments and to the better outcomes associated with early stage interventions. For example, late stage interventions tend to involve intensive treatment, including drug use and subsequent intensive monitoring of patients relative to early stage interventions. Similarly, early stage interventions tend to offer a higher potential for QALY gains than late stage disease. In the case of breast cancer, latestage ICERs were found to be 1.5 to 12 times higher in comparison with the early stage. The National Institute for Health and Care Excellence (NICE) subdivided early breast cancer into two major types, which are in situ cancer, mainly in the form of ductal carcinoma in situ (DCIS), and invasive cancer [31]. Based on the TNM classification of American Joint Committee for cancer, Dipiro et al. claimed that stage I and stage II breast cancer are often referred to as early stage breast cancer [32].

Nearly one in five patients diagnosed with advanced breast cancer are HER2 positive $[1,33$. Targeted therapy has proved to be pivotal in the management of HER2 positive breast cancer. In comparison with cytotoxic chemotherapy alone, the addition of HER2-targeted therapies markedly improves response rates, survival outcomes (in terms of Disease-Free Survival (DFS)/Progression-Free Survival (PFS) and Overall Survival (OS)) in patients with HER2-positive breast cancer treated in the neoadjuvant (treatment given to shrink the tumor before the main treatment), adjuvant (treatment given to help the main treatment) or metastatic (when the cancer has spread beyond the breast to other organs) settings [34]. Trastuzumab (Herceptin, Genetech), recombinant humanized monoclonal antibody, was the first medication in this group. Trastuzumab was approved for the treatment of both early stage and metastatic breast cancer in 2006 and 1998, respectively [35]. Several population-based studies reported 4-year survival rates after the first Trastuzumab treatment in patients with Early Breast Cancer (EBC) at nearly $90 \%$, and the 4 -year relapse-free survival rate in metastatic breast cancer at $76 \%[36,37]$. Trastuzumab generated $46 \%$ relative reduction in the risk of recurrence (Hazard Ratio: 0.54, 95\% Confidence Interval: $0.44-0.67)$ and $24 \%$ relative reduction in mortality (Hazard Ratio: 0.76, 95\% Confidence Interval: 0.47-1.23) [38]. This review aims to to provide a critical overview of economic evaluations of its use in HER2 positive early stage breast cancer.

\section{Health Economic Evaluation of Trastuzumab in the Treatment of Early Stage HER-2 Positive Breast Cancer}

Trastuzumab is expensive, for instance in the UK, to prevent one recurrent case, the estimated cost was $£ 400,000$ [39] while in other countries, one year's treatment per patient could cost between $\$ \mathrm{US} 60,000$ and $\$ \mathrm{Cdn} 35,000$ to 45,000 [40] (equivalent to $\$ 42,490$ to
$\$ 54,630, \mathrm{PPP}=1.214-2015)$ [41]. Its use as an adjuvant chemotherapy has been promising, with it being added in the recently updated Model List of Essential Medicine of WHO [42] despite its expense [40,43]. In fact, it is publicly funded in all Western European and most of Eastern European countries, resulting in significant financial burden on the healthcare system [43]. Given the number of potentially eligible women and the cost of the drug, it is not surprising that its use has been the subject of intense scrutiny especially in countries with publicly funded universal healthcare systems.

Several CEAs of the drug have been published in the light of nearly two decades of clinical study (Table 1) [44]. Assessing its relative value for money with specific regard to early stage disease is complicated by the fact that few evaluations of Trastuzumab in this setting provide clear definitions of what constitutes early breast cancer [39,45-49]. This lack of clarity complicates not only the assessment of its cost effectiveness in this setting but also of understanding the heterogeneity in estimates of its cost effectiveness in this setting.

It has been largely considered to be cost-effective in early-stage breast cancer by the majority of study authors $[30,44,50]$ with estimates ranging from dominant (that is cost saving) [51] to nearly $\$ 135,000 /$ QALY [33,52]-a value whose acceptability will depend on the ICER threshold in the context concerned. ICERs reported from healthcare payers perspective were roughly \$1796/QALY and \$21,830.11 QALY higher than those from societal and hospital perspectives, respectively [33]. However, in comparison with other countries, ICERs reported in Europe and the US studies were more likely to reveal unfavourable thresholds [33]. While the factors underlying these differences have not been explored one might speculate drug acquisition costs, improved understanding of how best to use the drug and select patients for treatment may underlie differences.

Ferrusi et al. indicated that major factors affecting Trastuzumab cost-effectiveness were the choice of testing strategy; drug price and the assumed duration of Trastuzumab benefit [44]. These authors went on to argue that while studies are reported in different countries, the models deployed in those countries often varied little beyond the unit costs used to monetise resource use, calling into question the independence of these studies. That said studies have reported on a range of factors that influence cost effectiveness.

\section{Duration of use, time horizon and age}

The short term use of Trastuzumab appears to generate more favourable ICERs than with its longer term use. For example, some analysis suggest that a 9-week Trastuzumab regimen could result in cost savings compared with 52 -week therapy $[44,53]$ but this warrants further investigation as the claim in based on a review of other reviews rather than a trial designed to explore this issue. With respect to age, Chan et al concluded that as an adjuvant therapy, Trastuzumab was cost-effective in women aged below 65 over a life-time horizon, but not cost-effective in patients aged over 75 or with a time horizon of less than 10 years [33]. Another study showed that time horizons shorter than 7.8 years compared to more than 7.8 years and patients over 75 compared to younger group resulted in higher incremental cost effectiveness of more than $€ 50,000 /$ QALY [45]. This number could be up to more than $€ 100,000 / \mathrm{QALY}$ in patients more than 79 years old compared to the under 79 [45]. While another review reported that Trastuzumab for those over 65 years old was not cost effective [50], care is warranted with this claim given it is based on the interpretation of previous studies the focus of which was not heterogeneity in ICERs related to age. Clearly there exists some uncertainty both as to the role 


\begin{tabular}{|c|c|c|c|c|c|c|c|}
\hline S. No. & Authors & Year & Country & $\begin{array}{l}\text { ICER estimate } \\
\text { Cost/QALY }\end{array}$ & $\begin{array}{l}\text { ICER estimate } \\
\text { Cost/LYG }\end{array}$ & Definition of comparator & $\begin{array}{l}\text { Definition of early } \\
\text { stage }\end{array}$ \\
\hline 1 & $\begin{array}{c}\text { Garrison et al. } \\
{[56]}\end{array}$ & 2007 & USA & $\begin{array}{c}\text { - Payer perspective: Lifetime } \\
\text { \$26,417/QALY; 20-year } \\
\text { horizon \$34,201/QALY } \\
\text { - Societal perspective: } \\
\text { Lifetime \$27,637/QALY }\end{array}$ & $\begin{array}{l}\text { - Payer perspective: } \\
\text { Lifetime } \$ 24,435 / \\
\text { LYG; 20-year horizon } \\
\$ 32,361 / \text { QALY }\end{array}$ & $\begin{array}{c}\text { Regimen without Trastuzumab } \\
\text { Paclitaxel q3w } \times 4 \text { or Paclitaxel qw } \\
\times 12\end{array}$ & $\begin{array}{l}\text { Based upon the } \\
\text { definition in the } \\
\text { NSABP B-31 and } \\
\text { NCCTG N9831 trials }\end{array}$ \\
\hline 2 & $\begin{array}{l}\text { Norum et al. } \\
{[40]}\end{array}$ & 2007 & Norway & $\begin{array}{l}-€ 19,176 / L Y G(\text { OS } 20 \%) \\
-€ 44,934 / L Y G(\text { OS } 10 \%)\end{array}$ & $\begin{array}{c}-€ 8,148 / L Y G \text { (OS } 20 \%) \\
-€ 30,290 / L Y G(O S \\
10 \%)\end{array}$ & $\begin{array}{c}\text { FEC100 regimen administered for q3w } \\
\text { x } 6 \text { without Trastuzumab } \\
\text { (FEC: fluorouracil, epirubicin, } \\
\text { cyclophosphamide) }\end{array}$ & $\mathrm{N} / \mathrm{A}$ \\
\hline 3 & $\begin{array}{l}\text { Millar and } \\
\text { Millward [78] }\end{array}$ & 2007 & Australia & \$A 22,793/QALY & $\$ A 13,730 / L Y G$ & Standard therapy & $\mathrm{N} / \mathrm{A}$ \\
\hline 4 & $\begin{array}{l}\text { Liberato et al. } \\
{[45]}\end{array}$ & 2007 & Italy and USA & $\begin{array}{c}€ 15,476(\$ 20,211) / Q A L Y \\
\text { Discounted ICER: } € 14,861 \\
(\$ 18,970) / Q A L Y\end{array}$ & $\mathrm{~N} / \mathrm{A}$ & $\begin{array}{l}\text { Regimen without Trastuzumab } \\
\text { Paclitaxel q3w } \times 4 \text { or Paclitaxel qw } \\
\times 12\end{array}$ & $\begin{array}{l}\text { Based upon the } \\
\text { definition in the } \\
\text { NSABP B-31 and } \\
\text { NCCTG N9831 } \\
\text { trials. }\end{array}$ \\
\hline 5 & $\begin{array}{l}\text { Kurian et al. } \\
\text { [62] }\end{array}$ & 2007 & USA & $\$ 39,982 / \mathrm{QALY}$ & $\mathrm{N} / \mathrm{A}$ & $\begin{array}{l}\text { Doxorubicin+Cyclophosphamide } q 3 w \\
\times 4, \text { followed by paclitaxel qw } \times 12\end{array}$ & $\mathrm{~N} / \mathrm{A}$ \\
\hline 6 & $\begin{array}{l}\text { Dedes et al. } \\
\qquad[79]\end{array}$ & 2007 & Switzerland & $\mathrm{N} / \mathrm{A}$ & $\begin{array}{c}€ 40,505 / I Y G \text { (after } 10 \\
\text { years) } \\
€ 19,673 / \mathrm{LYG} \text { (after } 15 \\
\text { years) }\end{array}$ & $\begin{array}{l}\text { Adjuvant treatment after surgical } \\
\text { therapy without Trastuzumab }\end{array}$ & $N / A$ \\
\hline 7 & $\begin{array}{l}\text { Neyt et al. } \\
\text { [53] }\end{array}$ & 2008 & Belgium & Not reported & $\begin{array}{l}€ 3,383-€ 55,518(15 \\
\text { subgroup analysis) }\end{array}$ & Standard care & $\mathrm{N} / \mathrm{A}$ \\
\hline 8 & $\begin{array}{l}\text { Macedo et al. } \\
{[80]}\end{array}$ & 2010 & Portugal & $\begin{array}{l}€ 10,595 / L Y G \text { (direct cost } \\
\text { only) } \\
€ 7,789 / L Y G \text { (indirect cost) }\end{array}$ & $\begin{array}{l}€ 10,067 / L Y G \text { (direct } \\
\text { cost only) } \\
€ 7,400 / L Y G \text { (indirect } \\
\text { cost) }\end{array}$ & Standard care & $\mathrm{N} / \mathrm{A}$ \\
\hline 9 & $\begin{array}{l}\text { Purmonen } \\
\text { et al. } \\
\text { [46] }\end{array}$ & 2011 & Finland & $€ 12,000 / Q A L Y$ & $€ 9,300 / L Y G$ & Standard treatment & $\begin{array}{l}\text { Based on FinHER } \\
\text { trial }\end{array}$ \\
\hline 10 & $\begin{array}{l}\text { Hall et al. } \\
\text { [64] }\end{array}$ & 2011 & UK & $\begin{array}{c}£ 25,803 / \mathrm{QALY} \\
(56 \% \text { probability }<£ 30,000)\end{array}$ & $\mathrm{N} / \mathrm{A}$ & Chemotherapy without Trastuzumab & $\mathrm{N} / \mathrm{A}$ \\
\hline 11 & $\begin{array}{l}\text { Hedden et al. } \\
\quad[60]\end{array}$ & 2012 & Canada & $\$ 13,095 / \mathrm{QALY}$ & $\$ 15,492 / L Y G$ & Standard chemotherapy & $\mathrm{N} / \mathrm{A}$ \\
\hline 12 & $\begin{array}{l}\text { Buendia et al. } \\
{[47]}\end{array}$ & 2013 & Colombia & $\$ 71,491 / \mathrm{QALY}$ & $\mathrm{N} / \mathrm{A}$ & Standard chemotherapy & $\mathrm{N} / \mathrm{A}$ \\
\hline 13 & $\begin{array}{l}\text { Aboutorabi } \\
\text { et al. } \\
\text { [59] }\end{array}$ & 2015 & Iran & $\$ 51,302 / \mathrm{QALY}$ & $\$ 54,223 / L Y G$ & $\begin{array}{l}\text { Adjuvant chemotherapy } \\
\text { alone: Docetaxel, doxorubicin, } \\
\text { cyclophosphamide } \\
\text { q3w } \times 6\end{array}$ & $\mathrm{~N} / \mathrm{A}$ \\
\hline 14 & $\begin{array}{l}\text { Lang et al. } \\
\quad[49]\end{array}$ & 2016 & Taiwan & $\$ 51,863 / \mathrm{QALY}$ & $\mathrm{N} / \mathrm{A}$ & $\begin{array}{l}\text { Commonly used chemotherapy } \\
\text { regimen for HER-2+ early breast } \\
\text { cancer women without Trastuzumab } \\
\text { (such as combination of docetaxel } \\
\text { or paclitaxel, doxorubicin and } \\
\text { cyclophosphamide) }\end{array}$ & $\mathrm{N} / \mathrm{A}$ \\
\hline
\end{tabular}

Table 1: Summarizing the cost effectiveness analysis of Trastuzumab in the treatment of early stage HER2 positive breast cancer.

of age where care is warranted given the extrapolation of estimates from other studies.

\section{Study perspective}

Other factors that have been shown to influence the cost effectiveness of Trastuzumab include the perspective adopted for the study [2]. Most studies evaluated direct cost from a third party payer perspective $[47,51,54,55]$. This decision likely reflected access to data, details of resource use and reimbursements by third party payers being generally more readily available than details of out of pocket expenditures or where costs relate to absenteeism or presenteeism. In studies adopting a societal perspectives, many included this as part of an analysis undertaken from the payer's perspective [40,56,57]. From the payer's perspective, most studies included as costs HER-2 testing, drug acquisition and drug administration costs, as well as supportive medications $[47,54,55]$, cardiac monitoring $[47,55]$, costs of palliative Trastuzumab $[51,54,55]$, cost of local and distant cancer recurrences
$[47,51,54,55]$ as well as the cost of different chemotherapy-related adverse events [47]. In studies reporting from a societal perspective studies reported productivity losses [51,56-58], transportation costs [56,57], out-of-pocket payments [43]. Assessing non-care costs is not straightforward. With respect to lost production, for example, as it is in general easier to calculate time off work during treatment, compared to the potential opportunity cost of future production, most studies scrutinized the former issue and made no reference to the latter. How appropriate this approach is, is open to debate [40]. Finally, unit cost is another crucial factor to take into account when trying to interpret cost effectiveness study. Unit costs are not available in all countries and the value accorded these can vary depending inter alia on the accounting procedure used to generate them, the structure, efficiency and bargaining power of the healthcare system from which they originate. These are again factors that can complicate the comparative analysis of ICERs even in instances where models differ ostensibly only in terms of the unit costs they apply to resource consumption. 


\section{Modelling}

The use of Trastuzumab in early stage breast cancer is relatively recent and it is not surprising therefore to find that most of the studies evaluating its cost effectiveness in this setting are model based given the paucity of data on longer term follow-up [33,40,50]. Modelling, however, often involves the use of many assumptions often based on adjustments of findings from earlier studies $[40,47,55,59,60]$. The reasonableness of these assumptions, however are central to the quality of model and the validity of its predictions. There is evident heterogeneity in the model based evaluations reported in the literature. For example, different studies use different modelling approaches, while most use a Markov modelling approach (including health-state transition model $[47,61,62]$, life-long state transition model [63], a discrete-state time dependent semi-Markov model [64]), others use dynamic models (dynamic life-cycle model [35]). The number of states modelled also varies markedly from 3 to 10 states of disease $[45,47,51,55,59,64]$, the variation reflecting in part the focus of the authors (such as cardiac toxicity, recurrence or relapse, HER2 testing and Trastuzumab regime) and the willingness of authors to balance complexity with transparency in models. How models are populated also varies though the relatively small number of trials relating to use of Trastuzumab in early stage breast cancer has served to limit heterogeneity here. Data from the HERceptin Adjuvant (HERA) $[53,54,65,66]$ trial has become the most commonly used source for evaluations of treatment in an early stage setting. Differences regarding DFS rates (disease-free state), duration of treatment effect, disease recurrence, cardiac toxicity, mortality, transition probability between trials will lead to significant differences in model parameters and choices in which outcomes to focus on can influence estimated ICERs even when these are derived from the same trial. As new studies report it is probable that cost effectiveness of Trastuzumab could change when new RCTs will be published.

Since 2010, new RCTs have been published with focus on collating the clinical outcome of Trastuzumab in neoadjuvant setting and in combination with other HER2 targeted medications (including pertuzumab and lapatinib) or other drugs used in breast cancer treatment (docetaxel, aromatase inhibitors, hormonal therapies). Some studies are phase II clinical trials for instance TBCRC 006, EORTC 10054, CHER-LOB [67-69], the others are phase III clinical trials such as the NOAH trial, NeoALTTO, CALGB 40601, NSABP protocol B-41, the Adjuvant Lapatinib and/or Trastuzumab Treatment Optimization Trial [70-73]. Such studies have the potential to produce parameters that will inform future modelling exercises.

\section{Cost- effectiveness thresholds}

In deciding whether a particular ICER represents value for money or not, ICERs must be compared with an appropriate threshold that reflects societal willingness to pay for the health gain achieved. Applying different thresholds is entirely reasonable given different countries may have different levels of income, different values for health gain and indeed different values for health gain related to specific diseases. Therefore, it is crucial for the authorities in different settings to be aware of this when interpreting the corresponding ICERs and making decision related to oncological drugs [29,33]. Although thresholds do differ [33] and cost effectiveness acceptability curves provide the opportunity to assess the likelihood of an intervention being deemed to be cost effective at various thresholds, it remains the case that these thresholds are indicative rather than proscriptive when it comes to reimbursement decisions. While, for example, the National Institute for Clinical Excellence (NICE) in the United Kingdom applies the threshold of 20,000 to 30,000 British pounds/QALY gained [74] in practice interventions including those for early stage breast cancer may be approved for reimbursement above this level. In fact, the importance of the cost-effectiveness threshold in the UK has called for studies to explore. This is an area of research in its own right. Applying the method of estimating the WTP based on the existing value of preventing a statistical fatality, Mason et al. suggested that the WTP for a discounted QALY was nearly $£ 69,000$ (without adjustments) and $£ 31,000$ (with age adjustment, apply for young adults) [75]. Using the same technique but in Swedish population, Johannesson and Meltzer estimated a WTP per QALY gained of around US \$90,000 [28]. In Australia, George et al. applied revealed preference method to examine the recommendations made by the Pharmaceutical Benefits Advisory Committee from 1991-1996 and revealed that no treatment costing under Au\$39,800 per life year gained was rejected and none over Au $\$ 75,300$ was approved [76]. In terms of how the estimated ICER of Trastuzumab actually influences reimbursement decisions in different jurisdiction these and the potential budgetary impact of the drugs reimbursement are clearly important issues.

\section{Conclusion}

There have been numerous economic evaluations of Trastuzumab since it was first approved for use in breast cancer. Despite the fact that it was approved for use in early stage breast cancer in 2006, there have been relatively few evaluations of it in this context. Of those that have reported, most adopt a model based approach that rely heavily on one trial extrapolating from this using a variety of assumptions. This has allowed a number of systematic reviews of the literature to be published on the subject $[2,33,44,50]$. However, these have focused on comparing the conclusions of studies, in terms of the cost effectiveness ratio reported and some information related to modelling method, providing limited critical analysis of sources of variations or how best to reconcile the apparently conflicting conclusions of these studies. While best practice guidelines on modelling exist, few of the reviews have sought to assess the quality of evidence incorporating the insights these might afford into their analyses.

Three important contributions to the literature now seem timely. First the conduct of a systematic review that critically assesses the cost effectiveness of Trastuzumab in the treatment of early stage breast cancer would be useful. Such a review should assess the quality of model based assessments against established criteria for the production of economic models, heterogeneity in the interpretation of the term "early stage" and seek to identify the source of variation in reported ICERs. Second, some 11 years after the approval for use of Trastuzumab in the treatment of early stage HER2 positive breast cancer, longer term follow up data on cost and survival now exist [77]. A model based analysis that avails of data outside a trial setting with the potential inherent biases this might generate not seems timely. This seems preferable to resorting to assumptions around many parameters with however an extensive sensitivity analysis. Third, a budget impact analysis based on the acquired experience of the drugs deployment to accompany the economic evaluation has the potential to provide valuable insights for those considering its use in this setting or expanding its use to other settings.

\section{References}

1. Ginsburg O, Bray F, Coleman MP, Vanderpuye V, Eniu A, et al. (2017) The global burden of women's cancers: a grand challenge in global health. Lancet 389: $847-860$.

2. Diaby V, Tawk R, Sanogo V, Xiao H, Montero AJ, et al. (2015) A review of systematic reviews of the cost-effectiveness of hormone therapy, chemotherapy, and targeted therapy for breast cancer. Breast Cancer Res Treat 151: 27-40. 
Citation: Nguyen QNT, Nguyen HQ, O'Neill C (2017) A Critical Review of Economic Evaluations of Trastuzumab in the Treatment of Early Stage HER2 Positive Breast Cancer. Pharmacoeconomics 2: 111. doi:10.4172/2472-1042.1000111

Page 5 of 6

3. Ferlay J, Soerjomataram I, Dikshit R, Eser S, Mathers C, et al. (2012) Globocan (2012) Globocan cancer fact sheets e breast cancer. Int J Cancer 136 E359-E386.

4. McKeage K, Lyseng-Williamson KA (2008) Trastuzumab: a pharmacoeconomic review of its use in early breast cancer. Pharmacoeconomics 26: 699-719.

5. Breast Cancer Statistics (2014) Cancer research UK.

6. Gradishar WJ, Robert CH, Anderson BO, Fred VC, Balassanian R, et al. (2017) NCCN Guidelines Version 2. Panel Members Breast Cancer.

7. Martin E (2016) Concise Medical Dictionary (9th edn.). Oxford University Press

8. Winn AN, Ekwueme DU, Guy GP, Neumann PJ (2016) Cost-utility analysis of cancer prevention, treatment, and control: a systematic review. Am J Prev Med 50: $241-248$

9. Dieci MV, Orvieto E, Dominici M, Conte P, Guarneri V, et al. (2014) Rare breast cancer subtypes: histological, molecular, and clinical peculiarities. Oncologis 19: 805-813.

10. Cancer Genome Atlas Network (2012) Comprehensive molecular portraits of human breast tumors. Nature 490: 61-70.

11. Perou CM, Sùrlie T, Eisen MB, van De Rijn M, Jeffrey SS, et al. (2000) Molecular portraits of human breast tumours. Nature 406: 747-752.

12. Tamimi RM, Colditz GA, Hazra A, Baer HJ, Hankinson SE, et al. (2012) Traditional breast cancer risk factors in relation to molecular subtypes of breast cancer. Breast Cancer Res Treat 131: 159-167.

13. Yang XR, Chang-Claude J, Goode EL, Couch FJ, Nevanlinna H, et al. (2011) Associations of breast cancer risk factors with tumor subtypes: a pooled analysis from the breast cancer association consortium studies. J Natl Cancer Inst 103: 250-263.

14. Barnard ME, Boeke CE, Tamimi RM (2015) Established breast cancer risk factors and risk of intrinsic tumor subtypes. Biochim Biophys Acta Rev Cancer 1856: $73-85$

15. Anderson WF, Rosenberg PS, Prat A, Perou CM, Sherman ME, et al. (2014) How many etiological subtypes of breast cancer: two, three, four, or more? JNCI J Natl Cancer Inst 106: 165

16. Blows FM, Driver KE, Schmidt MK, Broeks A, van Leeuwen FE, et al (2010) Subtyping of breast cancer by immunohistochemistry to investigate a relationship between subtype and short and long term survival: a collaborative analysis of data for 10,159 cases from 12 studies. PLoS Med 7: e1000279.

17. Adrada BE, Miranda RN, Rauch GM, Arribas E, Shamanna RK, et al. (2014) Breast implant-associated anaplastic large cell lymphoma: sensitivity, specificity, and findings of imaging studies in 44 patients. Breast Cancer Res Treat 147: 1-14

18. Parise CA, Caggiano V (2014) Breast cancer survival defined by the er/pr/ her2 subtypes and a surrogate classification according to tumor grade and immunohistochemical biomarkers. J Cancer Epidemiol 2014: 1-11.

19. Chen L, Linden HM, Anderson BO, Li Cl (2014) Trends in 5-year survival rates among breast cancer patients by hormone receptor status and stage. Breast Cancer Res Treat 147: 609-616.

20. Howlader N, Noone AM, Krapcho M, Miller D, Bishop K, et al. (2014) SEER cancer statistics review, 1975-2011.

21. Taylor D (2017) The reality of economics for oncologists. Breast 33: 183-190.

22. Kamal KM, Covvey JR, Dashputre A, Ghosh S, Shah S, et al. (2017) A systematic review of the effect of cancer treatment on work productivity of patients and caregivers. J Manag Care Spec Pharm 23: 136-162.

23. Jönsson B, Wilking N (2014) Prevention and the economic burden of breas cancer. Moneycontrol.

24. Luengo-Fernandez R, Leal J, Gray A, Sullivan R (2013) Economic burden of cancer across the European Union: a population-based cost analysis. Lance Oncol 14: 1165-1174.

25. Bradley CJ, Oberst K, Schenk M (2006) Absenteeism from work: The experience of employed breast and prostate cancer patients in the months following diagnosis. Psychooncology 15: 739-747.

26. Lundh MH, Lampic C, Nordin K, Ahlgren J, Bergkvist L, et al. (2013) Changes in health-related quality of life by occupational status among women diagnosed with breast cancer-a population-based cohort study. Psychooncology 22: 2321 2331.
27. Azarkish F, Najmabadi KM, Roudsari RL, Shandiz FH (2015) Factors related to return to work in women after breast cancer in Iran. Iran Red Crescent Med J 17: e19978.

28. Gray AM, Clarke PM, Wolstenholme JL, Wordsworth S (2011) Applied methods of cost-effectiveness analysis in health care. Oxford University Press p: 313.

29. Dvortsin E, Gout-Zwart J, Eijssen EL, van Brussel J, Postma MJ (2016) Comparative cost-effectiveness of drugs in early versus late stages of cancer review of the literature and a case study in breast cancer. PLoS ONE 11: e0146551

30. Ferrusi IL, Marshall DA, Kulin NA, Leighl NB, Phillips KA (2009) Looking back at 10 years of trastuzumab therapy: what is the role of HER2 testing? A systematic review of health economic analyses. Per Med 6: 193-215.

31. Early and Locally Advanced Breast Cancer: Diagnosis and Treatment (2009) National Institute for Health and Care Excellence (NICE).

32. DiPiro JT, Talbert RL, Yee GC, Matzke GR, Wells BG, et al. (2014) Pharmacotherapy: a pathophysiologic approach (10 th $\mathrm{edn}$.$) . McGraw-Hill$ Education.

33. Chan ALF, Leung HW, Lu CL, Lin SJ (2009) Cost-effectiveness of trastuzumab as adjuvant therapy for early breast cancer: a systematic review. Ann Pharmacother 43: 296-303.

34. Daniels B, Lord SJ, Kiely BE, Houssami N, Haywood P, et al. (2017) Use and outcomes of targeted therapies in early and metastatic HER2-positive breast cancer in Australia: protocol detailing observations in a whole of population cohort. BMJ Open Oncol 7: 1-12.

35. Garrison LP, Veenstra DL (2009) The economic value of innovative treatments over the product life cycle: the case of targeted trastuzumab therapy for breast cancer. Value Health 12: 1118-1123.

36. Bonifazi M, Franchi M, Rossi M, Zambelli A, Moja L, et al, (2014) Long term survival of HER2-positive early breast cancer treated with trastuzumabbased adjuvant regimen: A large cohort study from clinical practice. Breast 23: $573-578$.

37. Gallagher CM, More K, Masaquel A, Kamath T, Guerin A, et al. (2016) Surviva in patients with non-metastatic breast cancer treated with adjuvant trastuzumab in clinical practice. Springerplus 5: 395.

38. Trastuzumab for the adjuvant treatment of early-stage HER2-positive breast cancer (2006) National Institute for Health and Care Excellence.

39. McLaren EH (2005) Adjuvant trastuzumab for breast cancer: editorial does not mention health economics of drug. BMJ 331: 1203.

40. Norum J, Olsen JA, Wist EA, Lonning PE (2007) Trastuzumab in adjuvan breast cancer therapy. A model based cost-effectiveness analysis. Acta Oncol 46: 153-164

41. Eurostat-OECD Eurostat-OECD Data on Purchasing power parities (PPP) 2000-2016.

42. World Health Organization (WHO) (2015) The selection and use of essential medicines report of the WHO expert committee.

43. Cherny N, Sullivan R, Torode J, Saar M, Eniu A (2016) ESMO European Consortium Study on the availability, out-of-pocket costs and accessibility of antineoplastic medicines in Europe. Ann Oncol 27: 1423-1443.

44. Ferrusi IL, Leighl NB, Kulin NA, Marshall DA (2011) Do economic evaluations of targeted therapy provide support for decision makers? Am J Manag Care 17: $61-70$.

45. Liberato NL, Marchetti M, Barosi G (2007) Cost effectiveness of adjuvan trastuzumab in human epidermal growth factor receptor 2-positive breast cancer. J Clin Oncol 25: 625-633.

46. Purmonen TT, Pankalainen E, Turunen JHO, Asseburg C, Martikainen JA (2011) Short-course adjuvant trastuzumab therapy in early stage breast cance in Finland: cost-effectiveness and value of information analysis based on the 5-year follow-up results of the Fin Her Trial. Acta Oncol 50: 344-352.

47. Buendia JA, Vallejos C, Pichon-Riviere A (2013) An economic evaluation of trastuzumab as adjuvant treatment of early HER2-positive breast cance patients in Colombia. Biomedica 33: 411-417

48. Leung W, Kvizhinadze G, Nair N, Blakely T (2016) Adjuvant trastuzumab in HER2-positive early breast cancer by age and hormone receptor status: a costutility analysis. PLoS Med 13: 1-19. 
Citation: Nguyen QNT, Nguyen HQ, O'Neill C (2017) A Critical Review of Economic Evaluations of Trastuzumab in the Treatment of Early Stage HER2 Positive Breast Cancer. Pharmacoeconomics 2: 111. doi:10.4172/2472-1042.1000111

49. Lang HC, Chen HW, Chiou TJ, Chan AL (2016) The real-world costeffectiveness of adjuvant trastuzumab in HER-2/neu-positive early breast cancer in Taiwan. J Med Econ 19: 923-927.

50. Norum J (2006) The cost-effectiveness issue of adjuvant trastuzumab in early breast cancer. Expert Opin Pharmacother 7: 1617-1625.

51. Lidgren M, Jonsson B, Rehnberg C, Willking N, Bergh J (2008) Costeffectiveness of HER2 testing and 1-year adjuvant trastuzumab therapy for early breast cancer. Ann Oncol Off J Eur Soc Med Oncol 19: 487-495.

52. Van Vlaenderen I, Canon J, Cocquyt V, Jerusalem G, Machiels J, et al. (2007) Adjuvant trastuzumab treatment in early stage breast cancer: cost-effectiveness in the belgian health care setting. Value Heal 10: 336

53. Neyt M, Huybrechts M, Hulstaert F, Vrijens F, Ramaekers D (2008) Trastuzumab in early stage breast cancer: A cost-effectiveness analysis for Belgium. Health Policy 87: 146-159.

54. Skedgel C, Rayson D, Younis T (2009) The cost-utility of sequential adjuvant trastuzumab in women with Her2/Neu-positive breast cancer: an analysis based on updated results from the HERA Trial. Value Health 12: 641-648.

55. Skedgel C, Rayson D, Younis T (2013) Is adjuvant trastuzumab a cost-effective therapy for HER-2/neu-positive T1bNO breast cancer? Ann Oncol Off J Eur Soc Med Oncol 24: 1834-1840.

56. Garrison LPJ, Lubeck D, Lalla D, Paton V, Dueck A, et al. (2007) Costeffectiveness analysis of trastuzumab in the adjuvant setting for treatment of HER2-positive breast cancer. Cancer 110: 489-498.

57. de Lima Lopes GJ (2011) Societal costs and benefits of treatment with trastuzumab in patients with early HER2neu-overexpressing breast cancer in Singapore. BMC Cancer 11: 178.

58. Ramsey SD, Willke RJ, Glick H, Reed SD, Augustovski F, et al. (2015) Costeffectiveness analysis alongside clinical trials II-An ISPOR good research practices task force report. Value Heal 18: 161-172.

59. Aboutorabi A, Hadian M, Ghaderi H, Salehi M, Ghiasipour M (2015) Costeffectiveness analysis of trastuzumab in the adjuvant treatment for early breast cancer. Glob J Health Sci 7: 98-106.

60. Hedden L, O'Reilly S, Lohrisch C, Chia S, Speers C, et al. (2012) Assessing the real-world cost-effectiveness of adjuvant trastuzumab in HER-2/neu positive breast cancer. Oncologist 17: 164-171.

61. Chen W, Jiang Z, Shao Z, Sun Q, Shen K (2009) An economic evaluation of adjuvant trastuzumab therapy in HER2-positive early breast cancer. Value Health 12: 82-84.

62. Kurian AW, Thompson RN, Gaw AF, Arai S, Ortiz R, et al. (2007) A costeffectiveness analysis of adjuvant trastuzumab regimens in early HER2/neupositive breast cancer J Clin Oncol 25: 634-641.

63. Blank PR, Schwenkglenks M, Moch H, Szucs TD (2010) Human epiderma growth factor receptor 2 expression in early breast cancer patients: a Swiss cost-effectiveness analysis of different predictive assay strategies. Breast Cancer Res Treat 124: 497-507.

64. Hall PS, Hulme C, McCabe C, Oluboyede Y, Round J, et al. (2011) Updated cost-effectiveness analysis of trastuzumab for early breast cancer: a UK perspective considering duration of benefit, long-term toxicity and pattern of recurrence. PharmacoEconomics 29: 415-432.

65. Gianni L, Dafni U, Gelber RD, Azambuja E, Muehlbauer S, et al. (2011) Treatment with trastuzumab for 1 year after adjuvant chemotherapy in patients with HER2-positive early breast cancer: a 4-year follow-up of a randomised controlled trial. Lancet Oncol 12: 236-244.

66. Piccart-Gebhart MJ, Procter M, Leyland-Jones B, Goldhirsch A, Untch M, et al. (2005) Trastuzumab after adjuvant chemotherapy in HER2-positive breast cancer. N Engl J Med 35316: 1659-1672.
67. Rimawi MF, Mayer IA, Forero A, Nanda R, Goetz MP, et al. (2013) Multicenter phase II study of neoadjuvant lapatinib and trastuzumab with hormonal therapy and without chemotherapy in patients With human epidermal growth factor receptor 2-overexpressing breast cancer: TBCRC 006. J Clin Oncol 31: 1726-1731.

68. Bonnefoi H, Jacot W, Saghatchian M, Moldovan C, Venat-Bouvet L, et al. (2015) Neoadjuvant treatment with docetaxel plus lapatinib, trastuzumab or both followed by an anthracycline-based chemotherapy in HER2-positive breast cancer: results of the randomised phase II EORTC 10054 study. Ann Oncol 26: 325-332.

69. Guarneri V, Frassoldati A, Bottini A, Cagossi K, Bisagni G, et al. (2012) Preoperative chemotherapy plus trastuzumab, lapatinib, or both in human epidermal growth factor receptor 2-positive operable breast cancer: results of the randomized phase II CHER-LOB study. J Clin Oncol 30: 1989-1995.

70. Gianni L, Eiermann W, Semiglazov V, Manikhas A, Lluch A, et al. (2010) Neoadjuvant chemotherapy with trastuzumab followed by adjuvant trastuzumab versus neoadjuvant chemotherapy alone, in patients with HER2-positive locally advanced breast cancer (the NOAH trial): a randomised controlled superiority trial with a parallel HER. Lancet 375: 377-384.

71. Piccart-Gebhart M, Holmes E, Baselga J, de Azambuja E, Dueck AC, et al. (2016) Adjuvant lapatinib and trastuzumab for early human epidermal growth factor receptor 2-positive breast cancer: results from the randomized phase III adjuvant Lapatinib and/or Trastuzumab treatment optimization trial. J Clin Oncol 34: 1034-1042.

72. Robidoux A, Tang G, Rastogi P, Geyer CE, Azar CA et al. (2013) Lapatinib as a component of neoadjuvant therapy for HER2-positive operable breast cancer (NSABP protocol B-41): an open-label, randomised phase 3 trial. Lancet Oncol 14: 1183-1192.

73. Baselga J, Bradbury I, Eidtmann H, Di Cosimo S, de Azambuja E, et al. (2012) Lapatinib with trastuzumab for HER2-positive early breast cancer (NeoALTTO) a randomised, open-label, multicentre, phase 3 trial. Lancet 379: 633-640.

74. National institute for Health and Clinical Excellence (2009) Appraising lifeextending, end of life treatments.

75. Mason H, Jones-Lee M, Donaldson C (2009) Modelling the monetary value of QALY: a new approach based on UK data. Health Econ 18: 933-950.

76. George B, Harris A, Mitchell A (2001) Cost-effectiveness analysis and the consistency of decision making. Pharmacoeconomics 19: 1103-1109.

77. Cameron D, Piccart-Gebhart MJ, Gelber RD, Procter M, Goldhirsch A, et al (2017) 11 years' follow-up of trastuzumab after adjuvant chemotherapy in HER2-positive early breast cancer: final analysis of the HERceptin Adjuvant (HERA) trial. Lancet 389: 1195-1205.

78. Millar JA, Millward MJ (2007) Cost effectiveness of trastuzumab in the adjuvant treatment of early breast cancer: a lifetime model. Pharmacoeconomics 25 429-442.

79. Dedes KJ, Szucs TD, Imesch P, Fedier A, Fehr MK, et al. (2007) Costeffectiveness of trastuzumab in the adjuvant treatment of early breast cancer: A model-based analysis of the HERA and FinHer trial. Annals of Oncology 18 : $1493-1499$.

80. Macedo A, Monteiro I, Andrade S, Cirrincione A, Ray J (2010) Costeffectiveness of trastuzumab in the treatment of early stages breast cancer patients, in Portugal. Acta Med Port 23: 475-482. 